\title{
Oral favipiravir for patients with delayed SARS-CoV-2 viral RNA clearance: a case series
}

Dian $\mathrm{Fu}^{1,2+}$, Ruiyuan $\mathrm{Cao}^{3+}$, Lei $\mathrm{Zhao}^{3+}$, Wei $\mathrm{Li}^{3+}$, Wu Zhong ${ }^{3^{*}}$ and Jiqiu Wen ${ }^{1,2^{*}}$

Keywords: Favipiravir, SARS-CoV-2, COVID-19, viral RNA persistence

\section{Dear Editor,}

The COVID-19 pandemic has caused 14,893,706 infections and 613,879 deaths in 188 countries worldwide as of July 22, 2020, posing the largest world health crisis [1]. Although the pandemic is well controlled in China and the incidence is currently very low, we have observed a number of patients with delayed SARS-CoV-2 viral RNA clearance in the upper respiratory tract (more than 30 days), which combined with asymptomatic carriers, limits the prospect of eliminating the disease. The emergence of patients with delayed viral RNA clearance and healthy viral carriers is a major concern, not only in terms of disease control, but also due to the possible long-term damage to the patients' health. Previously, we have reported that favipiravir, a broad-spectrum antiviral drug approved in Japan and China, potently inhibits SARS-CoV-2 with a 50\% effective concentration $\left(\mathrm{EC}_{50}\right)$ of $61.88 \mu \mathrm{M}$ in vitro, indicating its antiviral potential [2]. Notably, favipiravir significantly reduced the time to viral clearance in an open-label nonrandomized controlled trial [3]. Here, we report a series of patients with considerably delayed SARS-CoV-2 RNA clearance and the treatment efficacy of favipiravir in this population.

\footnotetext{
* Correspondence: zhongwu@bmi.ac.cn; wjqkidney@hotmail.com

${ }^{\dagger}$ Dian Fu, Ruiyuan Cao, Lei Zhao and Wei Li contributed equally to this work. ${ }^{3}$ National Engineering Research Center for the Emergency Drug, Beijing Institute of Pharmacology and Toxicology, Beijing 100850, China

${ }^{1}$ National Clinical and Research Center of Kidney Diseases, Jinling Hospital, Nanjing University School of Medicine, Nanjing 210002, China

Full list of author information is available at the end of the article
}

From March 26, 2020, we administered oral favipiravir (two doses of $1600 \mathrm{mg}$ on day 1 and $600 \mathrm{mg}$ twice per day on days $2-10$ or until SARS-CoV-2 RNA negative) to nine asymptomatic rehabilitation patients. Eight patients were analyzed, and one patient was lost to follow-up due to transfer to another hospital. Of the eight patients included in this analysis, one received the full 10-day course of favipiravir, and seven received 4 to 9 days of favipiravir treatment.

The demographic and clinical characteristics of the eight patients are shown in Table 1 . The median duration of positive detection of SARS-CoV-2 viral RNA in patients before the initiation of favipiravir treatment was 61.0 days (interquartile range, 52.8 to 67.3 days). Coexisting conditions included hypertension (four patients), diabetes (two patients), coronary heart disease (one patient), and malignant tumor (two patients). No interruption of treatment occurred due to adverse reactions.

Over the 14-day follow-up period, the median duration of viral shedding was 3 days (interquartile range, 2 to 6 days) and one patient remained SARS-CoV-2 RNA-positive after 14 days (Fig. 1a). Notably, seven of eight patients showed a rapid viral clearance within 6 days. One patient kept sustained positive detection of SARS-CoV-2 viral RNA in the upper respiratory tract during the 14-day follow-up (Fig. 1b). The persistence of viral RNA detection in individual patients is shown in Fig. 1c. Seven patients were discharged after two consecutive negative viral RNA tests performed at 
Table 1 Demographic and clinical characteristics of patients

\begin{tabular}{ll}
\hline Characteristic & Patients $(\mathbf{N}=\mathbf{8})$ \\
\hline Median age (IQR), years & $60.5(47.5-68.5)$ \\
Male sex, no. (\%) & $4(50.0)$ \\
Oxygen support, no. (\%) & 0 \\
Body mass index (kg/m²), median (IQR) & $22.2(20.0-26.8)$ \\
Median duration of positive RNA detection before favipiravir & $61.0(52.8-67.3)$ \\
therapy (days), median (IQR) & \\
Other therapies before favipiravir therapy, no. (\%) & \\
Chloroquine phosphate & $4(50.0)$ \\
Umifenovir & $3(37.5)$ \\
Entecavir & $1(12.5)$ \\
Lianhua Qingwen granules & $2(25.0)$ \\
Thymopeptides & $4(50.0)$ \\
Pidotimod & $4(50.0)$ \\
Plasma transfusion & $2(25.0)$ \\
Coexisting conditions, no. (\%) & \\
Any condition & \\
Hypertension & $6(75.0)$ \\
Diabetes & $4(50.0)$ \\
Coronary heart disease & $2(25.0)$ \\
Malignant tumor & $1(12.5)$ \\
IgG immunoglobulin level (AU/mL), median (IQR) & $2(25.0)$ \\
& $12.5(5.1-25.2)$ \\
\hline
\end{tabular}

IgG immunoglobulin $\mathrm{G}$, IgM immunoglobulin $\mathrm{M}, \mathrm{IQR}$ interquartile range least $24 \mathrm{~h}$ apart. The patients were followed for about 1-2 months for the detection of viral nuclear acid in the throat swabs, and the patients remained negative (Fig. 1d).

It has been reported that the persistence of intestinal SARS-CoV-2 shedding in some patients has led to their re-admission after their pneumonia had resolved [4]. Antiviral therapies appear to be an important means to resolve the problem of viral persistence. Our study suggests that favipiravir is worth further investigation as a common and widely used method of treating asymptomatic convalescent patients and carriers. The small size of this cohort and the relatively short period of follow-up limit the strength of evidence obtained by this study, and the results should be interpreted with caution. However, the rapid elimination of viral RNA in seven of the eight patients strongly suggests that administration of favipiravir may have played a role in terminating the viral RNA persistence. Randomized controlled trials are required to determine the efficacy of favipiravir for terminating SARS-CoV-2 shedding in convalescent patients and healthy carriers with delayed viral clearance.
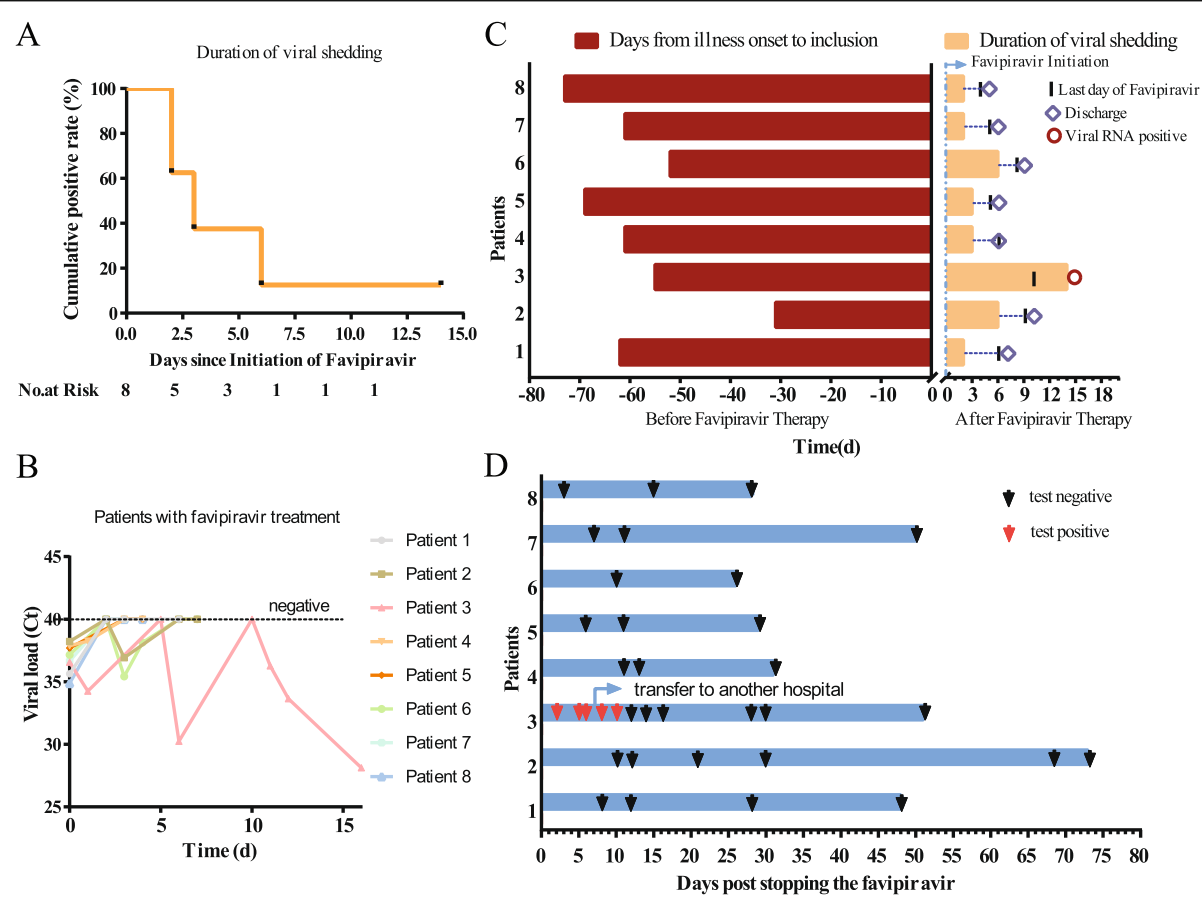

Fig. 1 The status of SARS-CoV-2 viral RNA detection in patients. a The Kaplan-Meier estimates of the duration of SARS-CoV-2 RNA detection after starting favipiravir. $\mathbf{b}$ The change from baseline of SARS-CoV-2 viral RNA load by quantitative real-time RT-PCR. $\mathbf{c}$ The detection of SARS-CoV-2 viral RNA in individual patients. Day 0 is the day on which treatment with favipiravir was initiated. For each patient, the red bar shows the duration of positive SARS-CoV-2 RNA in throat swabs from illness onset to inclusion, and the yellow bar shows the duration of viral shedding after starting favipiravir. The vertical line segment and diamond represent the last day of favipiravir treatment and the day of discharge, respectively. The red circle indicates that viral RNA was detected in the patient's swab at the end of the 14-day follow-up period. $\mathbf{d}$ Follow-up results after favipiravir stopped 


\section{Abbreviations}

COVID-19: Coronavirus disease 2019; SARS-CoV-2: Severe acute respiratory syndrome coronavirus 2

\section{Acknowledgements}

We thank the COVID-19 Huoshenshan Study Group and medical care personnel, who assisted in the care of the patients in this program: Xiaoli Xu, Xinyi Xia, Tangfeng LV, Jiong Liu, Songqing He, Jingjing Liang, Yulong Cai, Min Xu, and Zhenhua Gan (Jinling Hospital, Nanjing University School of Medicine, Nanjing, China): Yunhu Pan and Guang Chen (The 907th Hospital of Chinese People's Liberation Army Joint Logistics Support Force, Nanping, China); Xiao Wang and Min Tang (The 904th Hospital of Chinese People's Liberation Army Joint Logistics Support Force, Wuxi, China); Guoji Xia, Yongchun Xu Xiaochun Ouyang, Xi Ma, Qiang Wang, and Qianyong Yang (The 908th Hospital of Chinese People's Liberation Army Joint Logistics Support Force, Nanchang, China); Maozeng Lin (The 909th Hospital of Chinese People's Liberation Army Joint Logistics Support Force, Zhangzhou, China); and Yuancheng Hong (The 910th Hospital of Chinese People's Liberation Army Joint Logistics Support Force, Quanzhou, China).

\section{Authors' contributions}

WZ and JW contributed to the study design. DF and JW contributed to the collection of clinical data. RC, LZ, and WL contributed to the data analysis and manuscript preparation. All authors revised the manuscript and approved the final version of the manuscript. All authors agreed to authorship contributions.

\section{Funding}

This work was supported by the National Science and Technology Major Project (2018ZX09711003) and the National Key R\&D Program of China (2020YFC0841700)

\section{Availability of data and materials}

The datasets generated and/or analyzed during the current study are available from the corresponding authors on request.

\section{Ethics approval and consent to participate}

All studies were approved by the institutional review board of the Huoshenshan Hospital (HSSLL008). Trial registration: ChiCTR2000033491. Registered on 2 June 2020. All patients provided written informed consent to participate in the study.

\section{Consent for publication}

Not applicable

\section{Competing interests}

The authors declare that they have no competing interests.

\section{Author details}

National Clinical and Research Center of Kidney Diseases, Jinling Hospital, Nanjing University School of Medicine, Nanjing 210002, China. ${ }^{2}$ Wuhan Huoshenshan Hospital, Wuhan 430100, China. ${ }^{3}$ National Engineering Research Center for the Emergency Drug, Beijing Institute of Pharmacology and Toxicology, Beijing 100850, China.

Received: 27 July 2020 Accepted: 14 September 2020

Published online: 25 September 2020

\section{References}

1. Johns Hopkins University and Medicine. COVID-19 map. Johns Hopkins Coronavirus Resource Centre. https://coronavirus.jhu.edu/map.html. Accessed 22 July 2020.

2. Wang M, Cao R, Zhang L, Yang X, Liu J, Xu M, et al. Remdesivir and chloroquine effectively inhibit the recently emerged novel coronavirus (2019-nCoV) in vitro. Cell Res. 2020;30(3):269-71.

3. Cai Q, Yang M, Liu D, Chen J, Shu D, Xia J, et al. Experimental treatment with favipiravir for COVID-19: an open-label control study. Eng (Beijing). 2020. https://doi.org/10.1016/j.eng.2020.03.007.
4. Wang X, Zhou Y, Jiang N, Zhou Q, Ma W. Persistence of intestinal SARSCoV-2 infection in patients with COVID-19 leads to re-admission after pneumonia resolved. Int J Infect Dis. 2020;95:433-5. https://doi.org/10.1016/ j.jijid.2020.04.063

\section{Publisher's Note}

Springer Nature remains neutral with regard to jurisdictional claims in published maps and institutional affiliations.

\section{Ready to submit your research? Choose BMC and benefit from:}

- fast, convenient online submission

- thorough peer review by experienced researchers in your field

- rapid publication on acceptance

- support for research data, including large and complex data types

- gold Open Access which fosters wider collaboration and increased citations

- maximum visibility for your research: over $100 \mathrm{M}$ website views per year

At BMC, research is always in progress.

Learn more biomedcentral.com/submissions 